\title{
Indicator washcloth for detecting alkaline washing solutions to prevent dermatitis patients and babies from skin irritation
}

\author{
Cindy Schaude and Gerhard J. Mohr ${ }^{*}$
}

*Correspondence:
gerhard.mohr@joanneum.at
Joanneum Research
Forschungsgesellschaft
mbH - Materials,
Franz-Pichler-Straße 30,
8160 Weiz, Austria

*Correspondence: gerhard.mohr@joanneum.at Forschungsgesellscha $\mathrm{mbH}$ - Materials, 8160 Weiz, Austria

\begin{abstract}
A washcloth with a colour indicator appears green when immersed into skin friendly washing agents with a pH of around 6, and red when immersed into irritant washing solutions with a pH above 9 . This traffic light colour change of the washcloth helps parents and elderly people avoid allergic reactions caused by alkaline personal care products. The washcloth operates fully reversibly and thus can be used multiple times, and it can be washed without leaching because the dye chemistry is covalently immobilised to the fabric. Testing according to OekoTex 100 product class 1 approves contact with babies, certifying the high stability of immobilisation. The washcloth can be used for proper choice of skin care products and for general dermatology applications.
\end{abstract}

Keywords: Indicator washcloth, Optical sensor, Smart textiles, Dermatology, Neurodermitis, Allergy

\section{Introduction}

The development of smart textiles that yield information on the environment of human beings and their health status is very challenging. The integration of electronics into textiles has reached a high maturity for e.g. heating of napkins, shoe soles, gloves and seats. There have been many approaches to measure heart rate or blood pressure with sensors integrated into textiles (Cherenack and van Pieterson 2012), but none of the textiles have full flexibility, can be washed with a conventional washing machine or can be ironed at temperatures around $200{ }^{\circ} \mathrm{C}$ (Stoppa and Chiolerio 2014). These requirements for electronics, and especially their stable encapsulation to withstand humidity and caustic washing agents will probably be overcome in the next years. However, optical sensor technology is fully compatible with textile fabrication processes. Since textile dyes (reactive dyes) with specific indicator functions have become available (Mohr et al. 2008), stable textile sensors can be developed to fulfil all the requirements of the textile industry. Textile indicator dyes can be covalently linked to fibres containing hydroxyl and amino groups, they withstand washing at alkaline $\mathrm{pH}$ of conventional washing agents for $>50$ times, they react fully reversibly and are unaffected by ironing (Lobnik 2012).

The objective of the present study is to develop sensor textiles that show a colour change when human skin is exposed to irritating washing agents. This colour change

(c) The Author(s) 2017. This article is distributed under the terms of the Creative Commons Attribution 4.0 International License (http://creativecommons.org/licenses/by/4.0/), which permits unrestricted use, distribution, and reproduction in any medium, provided you give appropriate credit to the original author(s) and the source, provide a link to the Creative Commons license, and indicate if changes were made. 
must be clearly visible to the eye and easily understandable, i.e. a colour change from green to red (Van der Schueren and De Clerck 2012). Furthermore, the indicator dye has to be covalently immobilised to the textile, so that no leaching and thus no toxic effects for the human body are to be expected (Bafana et al. 2011; Malinauskiene et al. 2013). Finally, the textile (indicator) dyes have to be prepared using similar synthetic chemistry to conventional textile dyes, which means that the dyes can be prepared in the multi-kg range to produce textiles in large quantities in a cost-sensitive way.

In the present study, we have focussed on a textile indicator material that is not in continuous contact with the human body but nevertheless has to fulfil all requirements for clothing (OEKO-TEX ${ }^{\circledR}$ Standard 100, 2016). The indicator washcloths described in this work are useful for infants with highly sensitive skin (Dahlquist and Fregert 1979), for dermatitis patients (Seyfarth et al. 2011) and for elderly people (Kerscher 2011). The acid mantle of the skin has a pH of about 5.4-5.9, which is slightly acidic (Rippke et al. 2002). This protects the skin against bacteria, fungi and dryness. Therefore, skin-friendly (socalled $\mathrm{pH}$ skin-neutral) detergents, shampoos and shower gels have a slightly acidic $\mathrm{pH}$. Soaps and low-cost cleaning products however, are often alkaline ( $\mathrm{pH}$ above 8 ), which can lead to skin irritation in both infants and dermatitis patients. The indicator washcloths presented here show a colour change from green to red depending on the $\mathrm{pH}$ of the washing solution. Green signifies that the $\mathrm{pH}$ value is below 6.5 and is in the skinfriendly $\mathrm{pH}$ range, while red means that the $\mathrm{pH}$ is above 8.5 , indicating that skin irritation may occur.

Interestingly, the $\mathrm{pH}$ on the skin is not only relevant in monitoring atopic and contact dermatitis (Seidenari et al. 1998), but significant changes in $\mathrm{pH}$ on the skin to higher values were also found in both males and females in the case of non-insulin dependent diabetes mellitus (Yosipovitch et al. 1993). Clearly the same sensor textiles can also be used to measure the $\mathrm{pH}$ on the skin, as skin $\mathrm{pH}$ indicates the treatment efficiency of hyperhidrosis (Streker et al. 2010).

\section{Methods}

\section{Materials and measurements}

The chemicals for colouring the washcloth and the buffers for optical evaluation (sodium bicarbonate, sodium hydroxide, concentrated sulphuric acid, sodium dihydrogen phosphate, disodium hydrogen phosphate and hydrochloric acid, all of analytical reagent grade) as well as the inert dye disodium 1-amino-9,10-dioxo-4-[3-(2sulfonatooxyethylsulfonyl)-anilino]anthracene-2-sulfonate (RBBR) were obtained from Aldrich (Austria). The $\mathrm{pH}$ indicator dye 4-[4-(2-hydroxyethanesulfonyl)-phenylazo]2,6-dimethylphenol (GJM-503) was obtained from Joanneum Research Forschungsgesellschaft $\mathrm{mbH}$. The cotton washcloth W Vienna Style Supersoft was from Vossen $\mathrm{GmbH} \& \mathrm{Co}$. KG (Austria). The washings of the facecloth were performed in a Bauknecht Dynamic Sense WAK7778 laundry machine (Germany) using 40 and $60{ }^{\circ} \mathrm{C}$ programmes with approx. $50 \mathrm{~mL}$ of the washing agent Splendid Compact Color Universal Laundry Detergent from Spar (Austria) produced by the mibelle group (Switzerland). The procedure for the colouration of the washcloth has already been described in the literature (Mohr and Müller 2015). For localised application of the dyes onto the washcloths, a dyeing solution was sprayed through a template and the washcloths later 
rinsed with water to remove all excess chemical reagents. A glass microelectrode $\mathrm{pH}$ meter (Hanna Instruments) was used to measure the $\mathrm{pH}$ of the buffered solutions. A $\mathrm{pH}$ buffer $\left(0.1 \mathrm{~mol} \mathrm{~L}^{-1}\right.$ sodium dihydrogen phosphate) was used and $\mathrm{pH}$ was adjusted to the desired value by adding $1.0 \mathrm{~mol} \mathrm{~L}^{-1}$ aqueous sodium hydroxide or $1.0 \mathrm{~mol} \mathrm{~L}^{-1}$ hydrochloric acid solution. The colour changes of the washcloths were monitored using a colour measurement device using the $\mathrm{a}^{*}$ axis (green-red) of the CIE L*a*b* colour space to define the sensitive range. The $\mathrm{p} K_{\mathrm{a}}$ values were calculated by taking the $\mathrm{a}^{*}$ values of each indicator washcloth and depicting them against $\mathrm{pH}$, fitting the corresponding data with the Boltzmann fit of OriginPro 8.6G, and calculating the points of inflection of the resulting sigmoidal graphs. Colour images were taken using a Nikon D5100 with an AF-S Nikkor 18-105 mm objective lens.

\section{Results and discussion}

\section{Colour changes and sensitive range of the indicator washcloth}

Commercially available white (uncoloured) washcloths have been coloured by reacting them with a dye solution composed of two water-soluble dyes, one $\mathrm{pH}$ indicator dye GJM-503 that shows a colour change from yellow to red and one unreactive blue dye RBBR (Fig. 1). Both dyes are covalently linked to the cellulose of the washcloths in order to guarantee full stability against repeated washing at elevated temperatures. By using two dyes simultaneously during the dyeing process, a mixture in colours is obtained. Rather than giving a colour change from yellow to red with the single indicator dye, which is not easily recognised by the naked eye, the addition of the blue dye gives colour changes from green to orange and finally to red (Figs. 2, 3). The resulting traffic light colour change is easily interpreted in terms of green indicating a skin-friendly $\mathrm{pH}$ while red indicates irritant washing solutions.

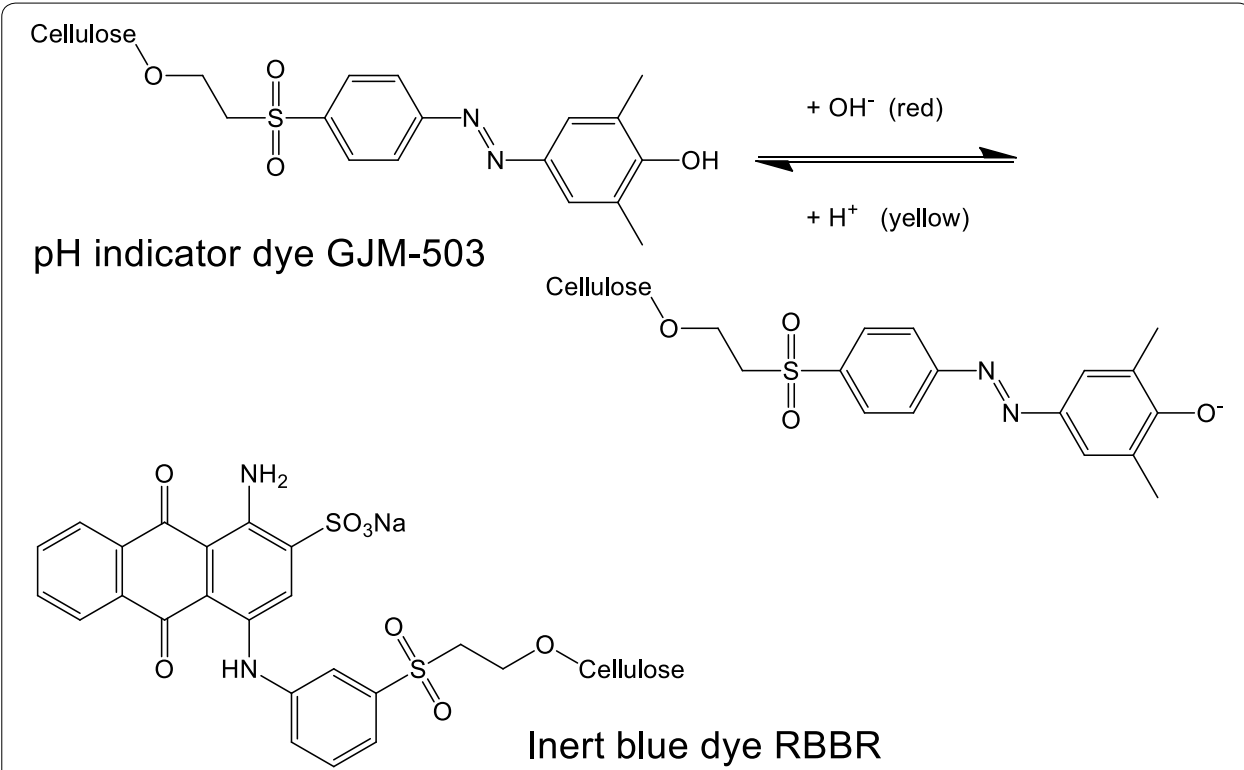

Fig. 1 Chemical structures of the $\mathrm{pH}$ indicator dye GJM-503 and the inert textile dye RBBR 


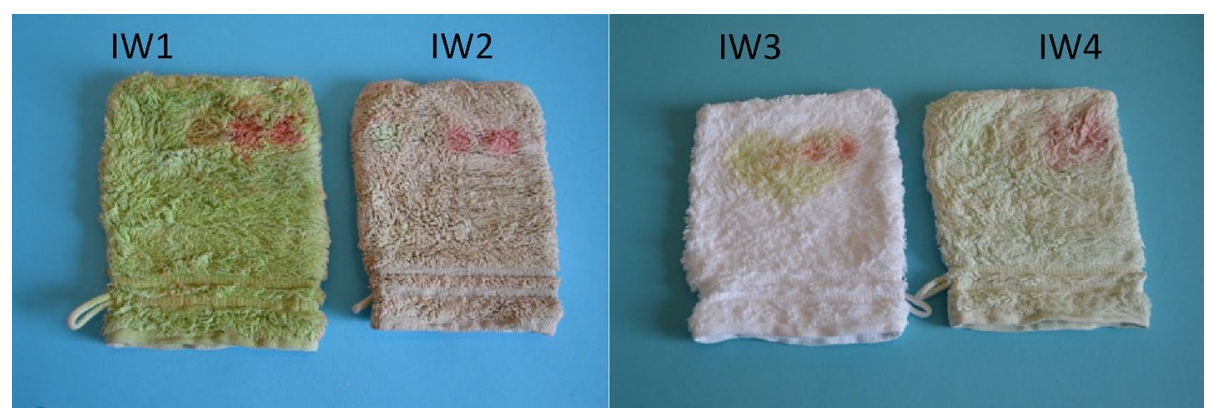

Fig. 2 Colour changes of the different indicator washcloths IW1-IW4 exposed to pH buffers 6, 7, 8, 9 (on each washcloth from left to right, giving four differently coloured spots corresponding to the $\mathrm{pH}$ changes from $\mathrm{pH}$ 6-9)

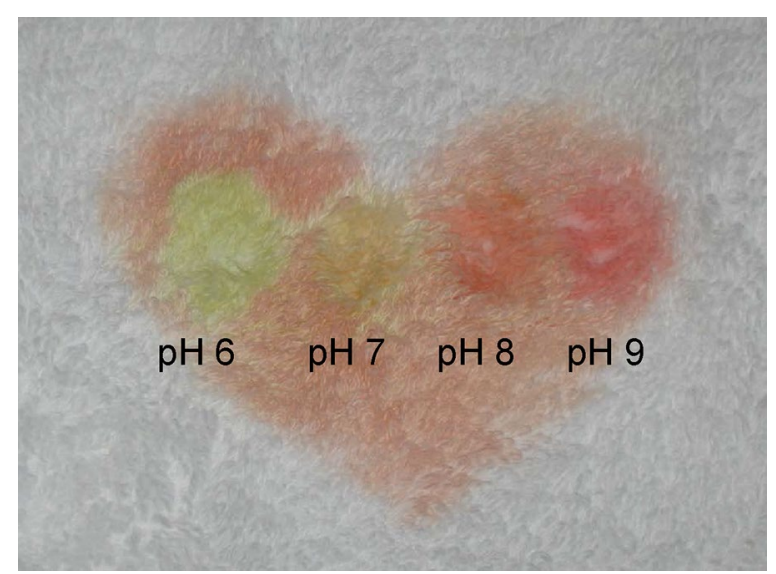

Fig. 3 Colour changes of the heart-shaped indicator pattern on the washcloth IW3 in detail

The washcloths have been dyed at two different colour intensities as the initial dark colouration not only appeared too strongly coloured but also consumed significantly larger amounts of dyes relative to the more weakly coloured (and thus more economical) washcloth (Fig. 2). Accordingly, two indicator washcloths $I W 1$ and $I W 2$ were coloured with a higher amount of both indicator and reference dye (IW2 was used for repeated laundry testing), while two indicator washcloths were coloured with half of indicator and inert dye, i.e. IW3 (which has colouration on only part of the washcloth) and IW4 that is fully coloured. Both types were evaluated in more detail; the strongly coloured washcloth $I W 2$ has been repeatedly washed under conventional laundry conditions i.e. 30 times at $40{ }^{\circ} \mathrm{C}$ and 50 times at $60{ }^{\circ} \mathrm{C}$ using an alkaline washing agent. Furthermore, washcloths $I W 1, I W 2$ and $I W 4$ have been evaluated at different temperatures to find out whether or not changes in temperature would affect the sensitive measurement range. The quantitative evaluation of the colour changes has been performed using a colour measurement device monitoring the CIE-L*a*b* colour space (Capeletti et al. 2012), and since the colour change is from green to red, the $\mathrm{a}^{*}$-axis has been chosen for calculating the $\mathrm{p} K_{\mathrm{a}}$ values and to define the sensitive range of the washcloths. 
The strongly coloured washcloth $I W 1$ shows a colour change in going from $\mathrm{pH} 6$ (green) via 7 (greenish yellow) to $\mathrm{pH} 8$ (orange-red) and $\mathrm{pH} 9$ (red) with a $\mathrm{p} K_{\mathrm{a}}$ value of around 7.3 (Fig. 4). Changing temperature from 4 to 20 to $40{ }^{\circ} \mathrm{C}$ does not significantly affect the $\mathrm{p} K_{\mathrm{a}}$ (Table 1), and thus the washcloth can be used with similar colour changes within the evaluated temperature range. Repeated washings of the strongly coloured washcloth IW2 caused a slight change in colouration, which most probably is due the real-world washing conditions chosen by the authors, i.e. leaching of dark dyes from coloured shirts, socks and trousers onto the washcloth. There is again only a minor effect of temperature on the sensitive range of this washcloth. However, in the case of the weakly coloured washcloth $I W 4$, the $\mathrm{p} K_{\mathrm{a}}$ value and thus the sensitive $\mathrm{pH}$ range is slightly increased, i.e. it is around 7.6 (Fig. 4). This corresponds more closely to cellulose-based transparent sensor layers using the same dye chemistry $\left(\mathrm{p} K_{\mathrm{a}}\right.$ of 7.71) (Mohr and Müller 2015) and indicates that for the strongly coloured washcloths, the high degree of colouration slightly decreases the observed $\mathrm{p} K_{\mathrm{a}}$ value (a phenomenon frequently observed for too large dye concentrations in optical sensors, see also Wolfbeis 1991). As a consequence, prior to practical application, every new batch of indicator washcloths has to be characterised in order to provide the accurate sensitive range.

\section{Practical use of the indicator washcloth}

The $\mathrm{pH}$ value is defined for aqueous solutions. Accordingly, the indicator washcloth only shows the $\mathrm{pH}$ value correctly when the measuring area is significantly wet. Dry washcloths may show colours that are different from the colour of the wet washcloth. Indeed, when drying the washcloth, initially red or orange washcloths may turn green within several days. This does, however, not affect the performance of the washcloth in aqueous environment.
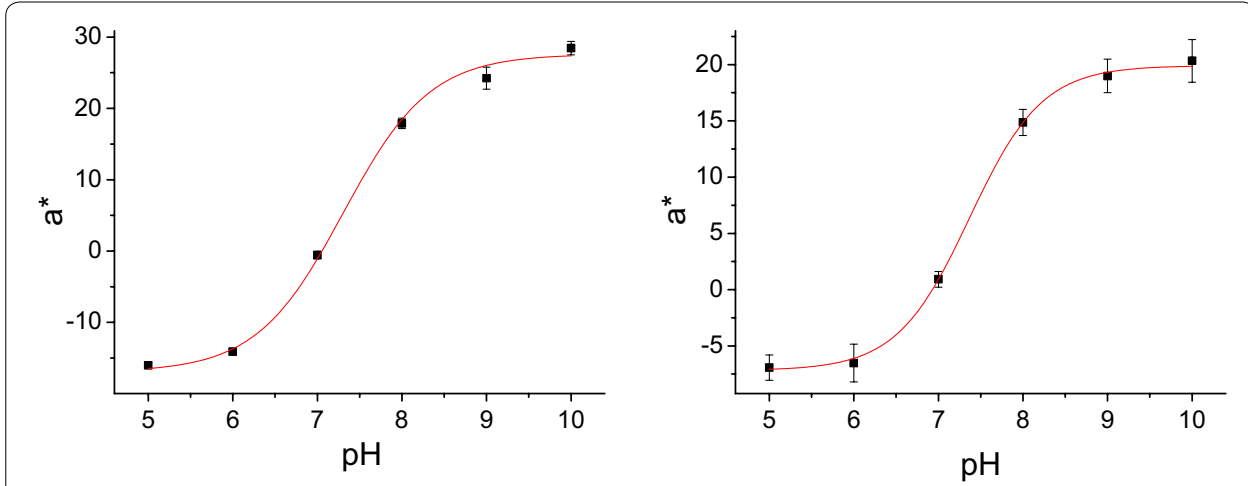

Fig. 4 Measurement range of the strongly coloured indicator washcloth IW1 (left) and the weakly coloured indicator washcloth IW4 (right) with $\mathrm{n}=5$

Table $1 \mathrm{p} K_{\mathrm{a}}$ values of indicator washcloths at different temperatures

\begin{tabular}{llll}
\hline Type of indicator washcloth & $\mathbf{p} \boldsymbol{K}_{\mathbf{a}}$ at $\mathbf{4}{ }^{\circ} \mathbf{C}$ & $\mathbf{p} \boldsymbol{K}_{\mathbf{a}}$ at $\mathbf{2 0}{ }^{\circ} \mathbf{C}$ & $\mathbf{p} \boldsymbol{K}_{\mathbf{a}}$ at $\mathbf{4 0}{ }^{\circ} \mathbf{C}$ \\
\hline IW1 (Strongly coloured) & 7.32 & 7.31 & 7.24 \\
IW2 (washed 80 times) & 7.28 & 7.42 & 7.12 \\
IW4 (Weakly coloured) & 7.58 & 7.63 & 7.57 \\
\hline
\end{tabular}

The sensitive range of indicator washcloth covers 1.5 units above and below the $\mathrm{p} K_{\mathrm{a}}$ value, with corresponding colour changes from green to orange and to red at increasing $\mathrm{pH}$ 
Due to the fact that towelling (terry cloth) used for the fabrication of washcloths is a thick material, the uptake of both water and cleaning agent by the cloth is quite significant. Consequently, before reusing the washcloth, it has to be rinsed with tap water several times to remove any traces of the previous cleaning product. Otherwise, rather than detecting the new $\mathrm{pH}$ value, residues of the previous cleaning product will define the measured $\mathrm{pH}$. In order to enable the parents or nursing staff to estimate the $\mathrm{pH}$ more accurately, a colour comparison chart may be used, but a yes-no decision may be sufficient, especially since there are predominantly two types of washing agents commercially available, either skin-friendly ones with a $\mathrm{pH}$ of around 5.5 or normal soaps with corresponding $\mathrm{pH}$ values around 9.

In terms of actual use, it is necessary to be aware of the fact that the washcloth is designed exclusively for cleaning products used in personal care. The sensitive range of the washcloth is between pH 6 and 9, and any further decreases in pH below 6 and increases above 9 does not further change the colour of the washcloth. So immersion into concentrated acids will also give a green colour.

\section{Stability of the indicator chemistry and certification}

Vinylsulfonyl dyes (also called Remazol dyes) are still widely used in textile chemistry in order to withstand washing at and above $60{ }^{\circ} \mathrm{C}$ for hundreds of times without major discolouration. The bond is very stable at acidic and moderately basic $\mathrm{pH}$, at which hydrolysis occurs (Wen et al. 1989), and it is not hydrolysed by enzymes as is the case for the amide bond. More recently, the dyes have also been used for the development of nonbleeding pH test strips (Neisius and Baeumer 1977), and in consequence for optical sensors (Wolfbeis 1992).

A first important requirement for textile use of azo dyes is that no possible products of their reductive cleavage are listed by the EU Directive 2002/61/EC. This requirement was met by the dyes used in this study. Furthermore, the strongly coloured washcloth $I W 1$ was certified according to OekoTex 100 product class 1 (contact with babies). The washcloth conformed to the requirements in terms of the absence of formaldehyde, the specifications concerning disperse azo dyes, heavy metal ions, halogenated phenols, tin organic compounds, surfactants, as well as rub fastness, fastness to perspiration and resistance to spittle. However, the $\mathrm{pH}$ of the washcloth ( $\mathrm{pH} 9$ of the aqueous extract) was higher than regulated by ISO 3071 (i.e. between 4.0 and 7.5). It was realised that the washing machine used for cleaning the washcloth was not rinsing textiles properly so that some small amount of alkaline washing agent was still present in the tested washcloth, causing an elevated $\mathrm{pH}$. This fact was also visible from the colour of the washcloth which was partially orange-red, especially at its thick corners. Therefore, the weakly coloured washcloth $I W 4$, prior to its certification, was rinsed twice by hand with tap water after washing with the laundry machine. Following this, the $\mathrm{pH}$ was found to be 6.6 and the washcloth fully conformed to the specifications for OekoTex 100 product class 1 .

\section{Conclusions}

The present indicator washcloth enables the determination of $\mathrm{pH}$ of washing solutions used in daily life, within a range which is relevant for well-being of human skin. The convenient format and easy interpretation make such textiles helpful for ambient assisted 
living, consumer care and medical diagnostics. The washcloth may be immersed into the cleaning solution (e.g. in the bathtub during the washing of babies or elderly people), or used directly during a shower. One may also test cleaning products prior to use by mixing a few drops of detergent with a little bit of water and then dipping the washcloth into the solution (https://youtu.be/oWDmWVPkNVo). The same sensing chemistry may also be integrated into wound dressings and cotton swabs to enable $\mathrm{pH}$ measurement in chronic wounds. Currently, we are working on indicator dyes for sodium and potassium ion to measure these ions in sweat.

\section{Author's contributions}

GJM conceived the study. CS and GJM designed the study. CS performed the experimental work. CS and GJM wrote the manuscript. Both authors read and approved the final manuscript.

\section{Acknowledgements}

This work was supported in part by Project 843582 "SenFood", by the femtech Project 840000 "PyzoTex", and by the Research Studios Austria Project 844724 "SmartColourTextiles" of the Austrian Research Promotion Agency (FFG). This support is gratefully acknowledged. We would also like to thank Jennifer Attard for stimulating discussions.

\section{Competing interests}

The authors declare that they have no competing interests.

Received: 25 July 2016 Accepted: 20 October 2016

Published online: 28 April 2017

\section{References}

Bafana, A., Saravana Devi, S., \& Chakrabarti, T. (2011). Azo dyes: Past, present and the future. Environmental Reviews, 19, $350-371$.

Capeletti, L. B., Dos Santos, J. H. Z., \& Moncada, E. (2012). Dual-target sensors: The effect of the encapsulation route on pH measurements and ammonia monitoring. Journal of Sol-Gel Science and Technology, 64, 209-218.

Cherenack, K., \& van Pieterson, L. (2012). Smart textiles: Challenges and opportunities. Journal of Applied Physics, 112, 091301.

Dahlquist, I., \& Fregert, S. (1979). Skin irritation in newborns. Contact Dermatitis, 5, 336-337.

Kerscher, M. (2011). Principles of treatment and protection for sensitive skin. Hautarzt, 62, 906-913.

Lobnik, A. (2012) Wearable optical chemical sensors, in: Intelligent textiles and clothing for ballistic and NBC protection, Part of the series NATO Science for Peace and Security Series B: Physics and Biophysics 29-52; ISBN: 978-94-007-0575-3.

Malinauskiene, L., Bruze, M., Ryberg, K., Zimerson, E., \& Isaksson, M. (2013). Contact allergy from disperse dyes in textilesA review. Contact Dermatitis, 68, 65-75.

Mohr, G. J., \& Müller, H. (2015). Tailoring colour changes of optical sensor materials by combining indicator and inert dyes and their use in sensor layers, textiles and non-wovens. Sensors and Actuators B, 206, 788-793.

Mohr, G. J., Müller, H., Bussemer, B., Stark, A., Carofiglio, T., Trupp, S., et al. (2008). Design of acidochromic dyes for facile preparation of $\mathrm{pH}$ sensor layers. Analytical and Bioanalytical Chemistry, 392, 1411-1418.

Neisius, K., Baeumer, W. (1977). Non-bleeding indicators and dyes used in pH determination process, US 4029597.

OEKO-TEX ${ }^{\circledR}$ Standard 100, OEKO-TEX ${ }^{\circledR}$ - International Association for Research and Testing in the Field of Textile Ecology, Edition 02/2016, ○ OEKO-TEX ${ }^{\circledR}$, Zurich.

Rippke, F., Schreiner, V., \& Schwanitz, H.-J. (2002). The acidic milieu of the horny layer: New findings on the physiology and pathophysiology of skin pH. American Journal of Clinical Dermatology, 3, 261-272.

Seidenari, S., Francomano, M., \& Mantovani, L. (1998). Baseline biophysical parameters in subjects with sensitive skin. Contact Dermatitis, 38, 311-315.

Seyfarth, F., Schliemann, S., Antonov, D., \& Elsner, P. (2011). Dry skin, barrier function, and irritant contact dermatitis in the elderly. Clinics in Dermatology, 29, 31-36.

Stoppa, M., \& Chiolerio, A. (2014). Wearable electronics and smart textiles: A critical review. Sensors, 14, 11957-11992.

Streker, M., Reuther, T., Verst, S., \& Kerscher, M. (2010). Axillary hyperhidrosis-efficacy and tolerability of an aluminium chloride antiperspirant. Hautarzt, 61, 139-144.

Van der Schueren, L., \& De Clerck, K. (2012). Coloration and application of pH-sensitive dyes on textile materials. Coloration Technology, 128, 82-90.

Wen, J., Zhenghua, Z., \& Kongchang, C. (1989). Study on the hydrolysis kinetics of vinylsulfonyl reactive dye-fiber bond. Dyes and Pigments, 10, 217-237.

Wolfbeis, O. S. (1991). Fiber optic chemical sensors and biosensors. Boca Raton, FL: CRC Press. ISBN 9780849355080

Wolfbeis, O. (1992). Sensor membrane for displaying the $\mathrm{pH}$ value of a sample, method of manufacturing the membrane, and its use, EP 606327.

Yosipovitch, G., Tur, E., Cohen, O., \& Rusecki, Y. (1993). Skin surface pH in intertriginous areas in NIPDM patients. Diabetes Care, 16, 560-563. 